\title{
Differentiated Use of the Cross-Lingual Strategy in Foreign Language Teaching: A Grounded Theory
}

\author{
Seyyed Ali Ostovar-Namaghi, Shabnam Norouzi \\ University of Shahrood, Shahrood, Iran
}

\begin{abstract}
Despite its potential in foreign language education, the cross-lingual strategy has been marginalized and stigmatized in many EFL contexts including language education in private language schools of Iran. This study aims to uncover the facilitative role of the cross-lingual strategy in foreign language instruction by theorizing experienced language teachers' practice. To this end, some experienced teachers were selected in line with the sampling procedures of Grounded Theory from famous English language institutes of Tehran, the capital city of Iran. Iterative data collection and analysis revealed that first language use can be differentiated based on learners' level of proficiency. For the beginners, it can be used to present classroom management rules, provide learners with the necessary classroom language and establish rapport. Similarly, at intermediate level L1 can be used to check mastery over the teaching points, give vocabulary equivalents, and explain writing rules. As for advanced learners, it can be used to explain the subtleties of grammar and provide learners with ideas to participate in classroom discussion and text processing.
\end{abstract}

Keywords: first language use, qualitative study, foreign language instruction, proficiency level

\section{Introduction}

Inspired by a long-lasting legacy of the natural method, many practitioners still believe that English must be learnt through English or an "intralingual strategy" and not by the "cross-lingual strategy" or first language use (Stern, 1992). This target language-only approach which asks learners and teachers to use the target language as the only means of instruction and communication in the language classroom can be traced back to: (1) the negative reaction towards the Grammar Translation Method which used the mother tongue as the main language of instruction and interaction; (2) the decline of contrastive analysis in language pedagogy; and (3) the once popularity of the Direct Method afterwards. Currently, however, there are lots of theoretical perspectives and empirical findings which support the constructive role of learners' mother tongue in language teaching. Nonetheless, in private language schools of Iran, the context of the present study, the intralingua strategy is the rule while the cross-lingual strategy is an exception. Although the latter is prohibited and stigmatized by supervisors and employers, there are some language teachers who use students' mother tongue to facilitate the teaching-learning process. This qualitative study will: (1) provide this minority group with a podium to voice their perspectives and (2) give the researchers the necessary data to uncover the potential uses of the cross-lingual strategy.

Seyyed Ali Ostovar-Namaghi, associate professor of TEFL, Ph.D., Department of Applied Linguistics, University of Shahrood. Shabnam Norouzi, M.A. TEFL candidate and practitioner, Department of Applied Linguistics, University of Shahrood. 


\section{Literature Review}

Using or not using the first language has been a controversy throughout the history of language teaching. There have been two groups of practitioners: the first group who follow an "intra-lingual strategy", i.e., a monolingual approach that rejects first language use, and the second group who follow a "cross-lingual strategy" that allows a judicious use of learners' first language or mother tongue (Stern, 1992). The negative attitude towards L1 use could be rooted in Grammar Translation Method (GTM) (Howatt, 1984) which used the first language overtly. Afterwards, the natural method totally rejected the use of the mother tongue in teaching a foreign or second language. Alternative methods that followed the Direct Method took different views towards L1 use. However, having entered the post method era, Brown (2000) recommends all ESL and EFL instructors adopt "a cautious, enlightened, and eclectic approach". This recommends teachers to use any device such as the first language to improve the quality of their teaching. This is also suggested by some experts who advise teachers to apply informed eclecticism in the classroom (Breen, 2001) which suggests that teachers apply as many effective, useful, and diverse activities as they can to meet the learners' needs.

Looking back at the history of language teaching, it can be seen that L2-only strategy has been overbearing in teaching English as a foreign language (TEFL) for more than half of the last century (Schweers, 1999) and some scholars of the field have been in favor of the intralingual strategy (McDonald, 1993; Turnbull, 2001). Krashen (1981), as an advocate of the monolingual approach, in his "second language acquisition" model states that people learn a second language in the same route as their first language; hence, the use of L1 in teaching L2 ought to be kept at the minimum level. From another view point, Sharma (2006) believes more exposure to L2 leads to more learning and enables learners to internalize the target language and get used to thinking in English. The next reason is that students have to produce comprehensible output, if they use their L1, nothing is negotiated in the TL and no learning happens (Swain, 1985). Also according to Cook (2001), separation and distinction of L1 and L2 would lead to successful learning. He also believes that the importance of L2 has to be made clear for the learners by its continuous use. Finally, Krashen (1981) with his input hypothesis is one of the major opponents of using the mother tongue in the classroom. In his theory, Krashen emphasizes the necessity of using the target language rather than students' mother tongue. Moreover, he sees any reduction of the L2 as a wasted opportunity for valuable input. However, Auerbach (1993) said that "evidence from research and practice is presented which suggest that the rationale used to justify English only in the classroom is neither conclusive nor pedagogically sound" (p. 5).

To support the cross-lingual strategy, Faltis (1990) mentions the new Concurrent Method that requires teachers to balance L1 and L2 use in the second language classrooms. In the same line, Nation (1978) believes that excluding the mother tongue from the instruction environment of the classroom could be the same as avoidance of using objects and pictures in the second language classroom. Finocchiaro and Brumfit (1983) believed that sensible use of L1 is acceptable where possible. Also Swan (1985) emphasized the agreement existed between L1 and L2. Atkinson (1987) recommends using the L1 equivalents for eliciting language and comprehension checking by both teachers and students. This can be done in the form of "How do you say...in English?". From another perspective, Hopkins (1988) believed that if second and foreign language learners are inspired to omit their own language from the L2 learning process and completely ignore it, they might feel identity-threatened. Skinner (1985) expressed the difficulties in connection with the use of L2 exclusively in the classroom. Excluding L1 from the L2 classroom is neither practical nor reasonable in terms of divesting 
learners and teachers of a useful tool. To support this idea, Stern (1992) argues that learner's L1 could have a reasonable place in FL classroom and tries to question the traditional belief of L2 only classrooms. By considering the psychological role of L1 in L2 classes from another point of view, Auerbach (1993) contends that using L1 would help L2 learners to take risks and experiment English; she also concludes that a sense of security will be aroused in learners in which their lived experiences would be validated; thus, they could be able to express themselves, because in such a way the psychological barriers have been removed and learners are allowed to have a more rapid progress.

Some studies have been undertaken to collect and analyze empirical evidence pro and con first language use. Through a qualitative research on university teachers and students, Schweers (1999) proposed judicious use of L1. He found that L1 is a good way to explain difficult concepts, help learners feel "less lost", and check learners' comprehension. However, Nazari (2008) tried to discover Iranian university students' perspectives toward the use of L1 and contrary to all previous studies, the results showed that the participants were reluctant to use their L1 (Persian). This was again in contradiction with what Cianflone (2009) found on mother tongue use in university English courses which showed that L1can be used for explaining the grammar, vocabulary items, and difficult concepts and for general comprehension. In another study, Rezvani and EslamiRasekh (2011) did an explanatory study on Iranian English foreign language teachers of elementary level in Isfahan, Iran and found judicious and skillful use of the first language can boost the quality of teaching. To verify the results of the previous studies, McMillan and Rivers (2011) by doing an attitude survey at a Japanese university with 29 native English speaker teachers discovered that use of L1 in FL classrooms can promote cognition, communication and social functions in language classrooms. Mahmudi and Yazdiamirkhiz (2011) explored the ideas of both teachers and students about L1 use in two pre-university classes in Ahvaz, Iran and found that excessive use of Persian (their L1) in L2 classes had a de-motivating effect on learners.

Following a pragmatic and scientific stream by the EFL (English as a Foreign Language) teachers was what NaciKayaoglu (2012) found by doing a study with 44 university English teachers. The results indicated that a great majority of the teachers took a practical and pragmatic position in the use of L1 instead of sticking to common opinions in the field. Also, Afzal (2013) in another study among 100 students and 10 teachers in Iran found that limited and judicious use of the mother tongue in the English classroom does not reduce students' exposure to English, but rather can increase the dosage of efficient teaching and learning. Also to discover Iranian teachers and parents' perspectives on the use of L1 in English language schools in Iran, Yaqubi and Pourmoid (2013) found that despite the latest theories which suggest using L1 in FL classrooms, Iranian teachers and parents did not have positive attitudes towards L1 use in language institutes. As a very new study in the field Kuhi and Abdolvash (2014) did a study on 40 Azerbaijani-Turki high school teachers in Iran to discover their attitudes towards the use of $\mathrm{L} 1$ in their teaching process. The results demonstrated that most of the teachers approved of using L1 in their foreign language teaching classrooms and its value in different occasions in ELT.

\section{Purpose of the Study}

This paper aims at theorizing experienced EFL teachers' perspectives on the judicious use of the cross-lingua strategy for learners at different levels of proficiency. To this end qualitative data were elicited by posing the general question, "What are the possible uses of the cross-lingual strategy for learners at different levels of proficiency?" Subsequent questions which narrow down the scope of the study and lead the 
researchers towards theoretical sampling were emerged from an initial analysis interviews with experienced language teachers who were willing to share their experience with the researchers.

\section{Research Method}

\section{Participants}

Researchers are in agreement that the participant selection process should remain open in a qualitative study as long as possible so that after initial accounts are gathered and analyzed, additional participants can be added who can fill gaps in the initial description or can expand or even challenge it (Dörnyei, 2007, p. 126). As a result, the number of the participants was not predetermined (Kwortnik, 2003) and this process is often referred to as "iteration" (Dörnyei, 2007). Using Snowball sampling, the researcher gathered interview data from experienced EFL teachers who were willing to share their views and experiences on the use of cross-lingual strategy with the researchers. Following Dörnyei (2007), the iterative process went on until we reached theoretical saturation.

Since language teachers who have no certificate in English may not be able to verbalize their thoughts and due to the fact that they are not familiar with theories of language teaching and learning, the researchers interviewed only TEFL graduates, i.e., those participants who held a B.A. or M.A. in language teaching and related fields. To add diversity to teachers' perspectives, we interviewed both male and female English teachers who spoke Persian as their mother tongue. The participants' aged from 25 to 60 . With respect to their teaching experience, it varied from 15 to 25 years. All of them have been teaching English as a foreign language in famous language schools of the capital city of Iran, Tehran.

\section{Data Collection and Analysis}

Unstructured interviews were used to collect the data for this study. According to Dörnyei (2007), this mode of interviewing allows maximum flexibility and enables the researchers to follow the interviewee in unpredictable directions, with only minimal interference from the research agenda. The participants were interviewed on the research question to discover their perceptions on the possible use of learners' mother tongue in their classrooms. Through snowball sampling they sampled interested and experienced participants and the iterative process of data collection and analysis continued until theoretical saturation was reached. To avoid any possible self-censorship on the part of the participants, the interviewees were assured that their real names and identities would remain unidentified and the information they present would not be revealed to any third parties.

Interviews were transcribed verbatim and to ensure that nothing important is missing, the transcripts of the interviews were shown for approval and possible modifications. Following Corbin and Strauss (2008), analysis was the interplay between the researcher and the data. The very first step in data analysis was to transform the recordings into a textual form (Dörnyei, 2007). Having transcribed and verified the written transcripts, in line with the principles and practices of grounded theory, the researchers started analysis which involved the coding of data and the identification of salient concepts and categories. According to Corbin and Strauss (2008) Theory coding is a three-step process: The first step in analyzing data is breaking the information down to pieces of and assigning conceptual categories to the data segments, i.e., open coding; the next step is to identify the interrelationship between these categories or what is technically known as axial coding; finally selective coding involves the highest level of abstraction, i.e., choosing a core category which not only describes the 
interrelationships between the emerged concepts and categories but also develops them into a unified whole. As finishing touches, through what is known as member checking, the final conceptualization was shown to the participants for verification.

\section{Results}

This study aimed to explore whether Iranian language teachers teaching in private language schools of Iran used learners' first language in EFL teaching. The researchers used Grounded Theory to collect and analyze qualitative data. Iterative data collection and analysis revealed that teachers used learners' first language selectively for different purposes at different levels of proficiency. All the participants admit that the English should be the main language of instruction and communication in the classroom, using learners' mother tongue must be kept to minimum, and it should be used tactfully, selectively, and effectively for the purposes and occasions which will be discussed in what follows.

\section{Beginning Levels}

A beginner has no prior image of and familiarity with the new language; thus, the use of the mother tongue in due situations seems necessary for them. Participants believe that the teaching and learning process can be facilitated for beginners if the language teacher uses learners' mother tongue to present classroom management rules, provide learners with the necessary classroom language, and establish rapport. In what follows all the subcategories are presented in details.

\section{Classroom Management}

The EFL classroom is the place where the learner aims at learning and communicating in the foreign language. Learners need to know the rules of the classroom and course-related rules. Since learners do not have the knowledge to understand these rules in the foreign language, most participants prefer to provide learners with these rules in their first language. Mina, one of the participants, believes:

At this level if I want to express the classroom rules of being absent, being late, scoring and the like, I would rather use Persian since my objective is making my learners understand what I mean. However, some teachers prefer to present rules in the second language and waste at least half an hour to express what they mean. For example, the teacher explains the classroom regulation as follows: If you are absent for one session, you will not lose any marks, however, if it is more than one session, for each session one point will be taken off your final score". Since he presented it in English, the learner does not understand it and at the end of the course he or she will ask you "Why did you take two points off my final score?" When you explain the reason, they say that they did not get what you meant.

Presenting classroom management rules in the first language facilitates the whole job. Teachers expect students to observe classroom rules and regulations. Beginners cannot understand what you mean and as a result they cannot act up to your expectations. Explaining this point, Pooya states:

You expect learners not to be late and not to be absent for more than one session. Moreover, you expect them to be polite and do their homework as required. If they do not know or understand what you mean, how do you expect them to do what they are told to do? Thus I present classroom rules in English and expect my students to observe them.

Presenting the regulations and the discipline of the course and the school in English is of no use. Teachers can use learners' first language to make sure students know what they should do. This is what Sahel believes when she says: 
It is a good idea to present classroom rules in students' mother tongue. Only then can they meet your expectations since they know what they should do and what you expect. These rules could be telling them how you expect them to study, how much they should study, how you score and the like.

Teachers and students have mutual expectations from each other. Students expect their teacher to teach effectively and on the other hand the teacher expects them to do what she or he says. Telling students these expectations and rules should be done in Persian at the beginning levels. Behrooz believes that these expectations should be stated in learners' first language at the beginning of the course. He says:

I expect my students to observe the classroom rules. I tell them that I expect no tardiness on the part of the learners or I categorically tell them that attendance is required. I also expect them to do their homework properly and the like. If I preset these rules in English, I cannot expect them to observe the rules since they cannot understand the instructions. It takes me less than fifteen minutes to present these rules in Persian.

\section{Bilingual Presentation of the Classroom Language}

If you tell what you expect of the learners in English, they cannot follow you and as such cannot meet your expectation. If you present them in English, you deprive learners of the authentic use of the second language. To solve this problem, participants believe that classroom language should be presented in learners' mother tongue and they should be juxtaposed with their equivalents in the target language. When the teacher made sure that the learners know what they mean in English, the teacher can do without the Persian forms. This strategy has two merits: (1) it ensures that students follow what you say and (2) they get cognizant with classroom language early on. In support of the bilingual approach Farhad states:

At low levels the teacher should definitely present the classroom language in L1 and then in L2; otherwise, the student understands nothing and will be disappointed. If you want the learners to follow you during the teaching and learning process, you need to do so. When I present classroom language with their L2 equivalents, I practice them a lot by using drills and after five or six sessions, there will be no L1 use for such purposes. The student will master the sentences and will no longer use the mother tongue.

Providing an English-speaking atmosphere in the classroom motivates learners to start speaking very early on. Telling them the sentences they need in English helps them to communicate what they mean. These sentences should be practiced with the learners. Shima believes that bilingual presentation of classroom language encourages learners to use the second language:

At silent levels, the learner has no background knowledge of English. So I present the classroom language in L1 with their L2 equivalents. Having practiced them for two or three sessions, the learners will use them later on. L2 is replaced with L1 gradually. This process may become long but finally L1 sentences will be replaced with L2.

Another point is that at these low levels, no explanation should be given about the structures of the sentences. The sentences are given to learners and learners are expected to memorize them without asking about their vocabulary or grammar. Telling learners the structures at this level will lead to negative transfer. This is a very important point and teachers should not involve students in any structural explanation. Shima believes:

When you present the classroom language, do not explain the structure even if your students ask. Do not say that this is the structure in Persian and the structure changes this way in English. This is not appropriate because interference may happen easily. On the other hand, if you involve students in repeating them and using them, they will develop a subconscious knowledge of these rules. 


\section{Establishing Rapport}

Teachers can make learning more enjoyable by building up rapport. Rapport also helps teachers motivate their learners. When learners are motivated, they put their heart to the tasks and assignments; hence, successful teachers try to motivate learners by establishing rapport. Rapport cannot be established through the target language since they do not follow what you mean. On the other hand, mother tongue facilities the process. Along these lines, Mina says:

Establishing rapport is very important but it cannot be done through English. Communication between teachers and students is very difficult. On the other hand communication between friends is much easier. Through language use he should tell the students that he is their friend rather than their teacher. If he says this in English, he cannot change the formal and tense classroom atmosphere into an informal friendly environment.

Sometimes the tasks and assignments are challenging and demanding. As such they may make students feel anxious. At the beginning level, L1 can be used to reduce anxiety. Anxiety makes the individual unreceptive to language input; thus, the learner fails to internalize the available target language and acquire the second language. When students feel anxious or uncomfortable, teachers can use learners' first language to calm down the learner and ensure them that the teacher is here to help them. In addition, sometimes using L1 to encourage students is more effective that using L2. To emphasize this notion, Sara states:

This happens a lot at basic levels. Students feel stressed and anxious when they cannot follow the lesson, understand the instructions and do the tasks and exercises. In these situations, I go to these learners and address them personally in their first language by telling them not to worry. When I give them some hints in their mother tongue, not only do they feel relaxed but also can do what they could not do when they were instructed in the target language.

\section{Intermediate Level}

At this level students usually speak and understand reasonably well and can use basic tenses but have problems with more complex grammar and vocabulary. However, since the classes are heterogeneous there are some learners who still have problems with basic points and tenses and fail to use them appropriately. To smooth the flow of the lesson and the communication process, learners' mother tongue can be minimally used for mastery check. It can also be used to provide the learners with any possible lapses in vocabulary, and explain writing rules.

\section{Mastery Check}

Teaching is not learning. Many teachers wrongly suppose that students learn and master the teaching points once they have been taught. There are many learners who do not learn what you teach. Still, there are those who have learned the grammatical structure and the words you have taught but they have difficulty in using them appropriately. To check whether they have mastered what you have taught, you can use their mother tongue minimally to check their mastery over the teaching material. Payam, one of the participants, states:

To check learners' mastery over what you have taught, using the mother tongue is a good technique. Having taught a grammatical structure, I use learners' mother tongue to check whether they have mastered it or not. For instance, having taught "present perfect tense", I present some sentences in Persian and ask them to say it them in English. If they can do it, I am sure that they have mastered what I have taught and I proceed with my teaching.

When you involve students in communication, it happens that they cannot express what they mean in English. Participants believe that they use the very same communication strategy for mastery check. Verifying 
this technique Amir states:

For instance if I had taught a grammatical structure and I noticed that it is used in the text I am teaching. I check whether they have mastered that grammatical structure by translating the target sentence into their mother tongue and ask the students, "How do you say...in English?". Since their books are closed, if they can present the sentence as it appeared in the text they were reading, I am sure that they can apply what they have learned in my class.

\section{Vocabulary Equivalents}

Vocabulary is crucial to both communication and comprehension; hence, it needs to be explicitly taught and learned. One cannot expect vocabulary to develop through simple exposure to written or spoken language. Having taught a new word, teachers should teach how it is used in actual communication by specifying it applications. According to the participants using learners' mother tongue can be an effective means of achieving this goal. There are occasions where you are not involved in vocabulary teaching but the meanings of some words are crucial. Amir states:

Imagine I have prepared a set of questions for my classroom to be discussed and I had to include some words in those questions such as "spouse" and "get along". When I go through the pairs I see some pairs have problems with some key words in their questions. Here my goal is not teaching vocabulary, I want to make them discuss, so I simply provide them with the L1 equivalents and say "همسر" and encourage them to continue their discussion in the target language.

In teaching vocabulary, sometimes explanation or giving synonyms exacerbates the situation. These explanations might be harder than the word itself and also the synonym could be more difficult than the word itself. Providing the learners with its L1 equivalent is a better and more effective technique in such cases. Sahar believes that sometimes it is the learners' mother tongue that shows what the word really means. Explaining this logic, she states:

For example, if we have the word "indicate", you can give "show" as its synonym and provide the learners with some examples. However, you see the student makes an example like this "I indicated the picture to my cousin". This shows that she has not internalized the correct meaning and usage. But if I say or write its equivalent on the board ("حاكى بودن"), this misunderstanding does not happen.

Although providing learners with synonyms is an effective way of clarifying the meaning of new words, when it comes to polysemy using synonyms will confuse the learners. Explaining this point, Pooya states:

For instance, imagine in a text you have the word "recoup". You can give several synonyms for that and you can also explain its meaning by giving examples. But I have experienced that none of these techniques can be as effective as giving its L1 equivalent only in one word. Then if you ask the learners to make examples and apply the word, you will see how good they can do it.

\section{Explaining Writing Rules}

Writing is one of the most difficult skills that foreign language learners are expected to acquire since it requires the mastery of a variety of linguistic, cognitive, and sociocultural competencies. As most teachers verify, teaching L2 writing is a challenging task. It follows conventions that are mutually understandable by the writer and the reader. In many cases, students write without following a specific structure and format and as such they do not follow writing rules. If you explain these rules in English, they may not get them. Moreover, it takes more time than using their mother tongue. Explaining the rules they should follow in learners' mother tongue help the teacher not to interrupt the process of writing. Supporting the notion, Farhad believes: 
To explain the format and the rules I see no problem using the first language because I am not practicing speaking or conversation. I want to attract their attention to the format. Therefore, I prefer to present them in L1 once and for all rather than see a lot of disordered pieces of writing the whole course. For example, I directly tell them if you want to relate things to each other use "in relation to" or "in accordance with" and then present some examples. You know, these learners have seen words like "in spite of" and "despite" a lot but still are not able to use them. I present the meanings of these connectors in L1 then present lots of examples in English.

When learners' first language helps to expound a salient and vital structure or point, I do not resist using that. This is what Mina states and believes one occasion that the first language could really assist is writing:

When I want to teach the characteristics of a formal letter, I would rather use the first language than tell them in English. This wastes a lot of time and at the end confuses them. Even at advanced levels learners cannot write a well-organized essay because rules of writing an essay have not been internalized. Presenting rules of essay writing in students' mother tongue greatly affects the quality of their essays.

\section{Advanced Level}

It is believed that at advanced levels there is no need to use L1. The reason is that learners have a good command of English and as such do not need their first language. However, tactful use of learners' mother tongue proves beneficial even at this level. Participants believe that at advanced level L1 can be used to explain subtleties of grammar use and provide learners with idea.

\section{Subtleties of Grammar}

English Grammar is complex and has lots of subtleties which make it difficult to master and use correctly and appropriately. Learners at this level usually know the most important structures and have mastery over them but they normally have problems with subtle points and their usages. Teachers cannot ignore these subtleties. According to the participants, learners' mother tongue can be used minimally and efficiently to raise learners' awareness of these subtleties. Verifying this point, Payam states:

At the advanced levels, there are some delicate points that should be explained in L1. There is no need to get involved in English explanations and make learners more confused. For example, when you are explaining the "embedded questions", you can first explain that an embedded question is not a question and they should avoid inversion. If they did not follow what you meant, you can explain the point in their mother tongue. Or as another example when you teach usages of the article "the", you can use the mother tongue to explain but it should be limited. This helps learners to understand the use of definite article.

Grammar is a rail on which the train of thought moves. If learners do not apply a grammatical rule correctly, it may lead to misunderstanding and confusion. Teachers are expected to help learners internalize grammatical structures in English. However, if the teacher sees that despite all the explanations and examples in the target language, learners still have difficulty using the structure to convey their intentions, the teacher can use mother tongue or bring examples of that structure in their mother tongue. This is very effective since it gives the students some grounds for comparison. Mina states:

I do not start teaching grammar using L1. I present my lesson with its details in English, and then I give them sentences in the first language and ask them to translate those sentences in English. At first, some students are not satisfied with such an exercise but when they see its effects, they are very thankful.

\section{Providing Learners With Ideas}

Activating what you have learnt is of great importance in learning a foreign language. At advanced levels, 
learners learner have little problem with structures and vocabulary. Although they know lots of words and structures they cannot participate in topic-based discussions. The reason is that they do not have any ideas related to the topic. Providing them with newspaper scraps or authentic materials in their mother tongue can give them lots of ideas in a very short time. Supporting this notion, Shima states:

I give my students Persian texts and then pair them off and let them discuss the issue. In normal situations if I just write a topic on the board and tell them to discuss, they fall short of ideas. But when I give them newspaper scraps or other authentic texts, they have lots of things to share.

Not having something to say is the main challenge at advanced levels. Moreover, in EFL contexts they do not have any access to authentic materials. However, they have access to lots of authentic materials in their mother tongue. For instance, they can listen to the news, listen to talk shows, and read stories in the mother tongue. Although they are in Persian, they give them lots of ideas. First language texts are good sources to be referred to by the learners. Verifying the use of Persian to have information-rich discussions, Sahar states:

I usually select Persian texts related to the issues presented in the textbook. For instance, if the topic is about heavy traffic, I tell them to listen to the news, read experts' views on traffic and then enter the discussion circle. I do not limit the discussion to the points presented in the textbook. Mother tongue helps me and the learners go beyond the text presented in the textbook. I am sure that the relevant information they get through their mother tongue helps them understand the information presented in the text more fully.

\section{Discussion}

This study aimed at exploring experienced language teachers' perceptions of using learners' mother tongue in teaching English. The results clearly show that the participants agree with using learners' mother tongue at different levels of proficiency. Even at advanced levels, authentic texts and talks in learners' mother tongue can enlighten the learners on issues presented in the textbook and lead to information-rich discussions in the target language. All in all, they believed that when it facilitates and catalyzes the teaching and learning process, mother tongue should be treasured rather than dogmatically avoided. This position is in line with Nation's (1978) position who believes that excluding the mother tongue from the instructional environment of the classroom could be the same as avoidance of using objects and pictures in the second language classroom. Previous studies show that learners' L1 can be used in presenting classroom language, explaining difficult concepts and checking learners' comprehension (Schweers, 1999), explaining the grammar and vocabulary items (Cianflone, 2009). This study added to the woodpile of L1 uses in teaching a foreign language by bringing the reader up-to-date with a differentiated use of $\mathrm{L} 1$ at different levels of proficiency.

\section{Conclusion}

Despite the facilitative and catalyzing role of L1 in foreign language instruction, in many contexts including the private language schools of Iran, first language use has been proscribed and stigmatized by both principals and supervisors. This clearly shows that in these contexts language teaching follows tradition and culturally accepted norms, which are theoretically unjustified, rather than principles of second language learning. In the light of the theoretical perspectives and empirical findings supporting first language use in foreign language teaching together with the mind-provoking and cogent perspectives presented by hardened and professional EFL practitioners, it is imperative that:

(1) Supervisors recognize the facilitative role of learners' first language and let the practitioners use this 
precious treasure when examples and explanations in the target language confuse the learners, derail the learners from communicating their ideas, and waste precious interaction time;

(2) Practitioners who truly believe that first language use aids foreign language education persuade the supervisors and other interested stakeholders through workshops and discussion panels.

\section{References}

Afzal, S. (2013). Using of the first language in English classroom as a way of scaffolding for both the students and teachers to learn and teach English. International Research Journal of Applied and Basic Sciences, 4(7), 1846-1854.

Atkinson, D. (1987). The mother tongue in the classroom: A neglected resource? ETL Journal, 41(4), 241-247.

Auerbach, E. (1993). Reexamining English only in the ESL classroom. TESOL Quarterly, 27, 9-32.

Breen, M. P. (2001). Navigating the discourse: On what is learned in the language classroom. In C. N. Candlinand N. Mercer (Eds.), English language teaching in its social context (pp. 306-322). New York: Routledge.

Brown, H. D. (2000). Principles of language learning and teaching (4th ed.). New York: Addison Wesley Longman.

Cianflone, E. (2009). L1 use in English courses at university level. ESP World, 8(22), 1-6.

Cook, V. (2001). Using the first language in the classroom. The Canadian Modern Language Review, 57(3), 402-423.

Corbin, J. M., \& Strauss, A. L. (2008). Basics of qualitative research: Techniques and procedures for developing Grounded Theory. London: Sage Publications, Inc..

Dörnyei, Z. (2007). Research methods in applied linguistics: Quantitative qualitative, and mixed Methodologies. Oxford: Oxford University Press.

Dujmovic, M. (2007). The use of Croatian in the EFL classroom. Metodicki Obzori, 2(1), 91-100.

Faltis, C. (1990). New directions in bilingual research design: The study of interactive decision making. In R. Jakobson and C. Faltis (Eds.), Language distribution issues in bilingual school (pp. 45-47). Clevedon, England: Multilingual Matters Ltd..

Finocchiaro, M., \& Brumfit, C. J. (1983). The functional-notional approach: From theory to practice. New York: Oxford University Press.

Hopkins, S. (1988). Use of mother tongue in teaching of English as a second language to adults. Language Issues, 2(2), 18-24.

Howatt, A. (1984). A history of English language teaching. Oxford: Oxford University Press.

Krashen, S. (1981). Second language acquisition and second language learning. Oxford: Pergamon.

Kuhi, D., \& Abdolvasg, M. (2014). Azerbaijan Turkic speaking English language teachers' attitudes towards the use of their mother tongue in English classes. International Journal of Research Studies in Language Learning, 3, 58-72.

Kwortnik, R. J. (2003). Clarifying "fuzzy" hospitality-management problems with depth interviews and qualitative analysis. Cornell Hotel and Restaurant Administration Quarterly, 44, 29-117.

Mahmudi, L., \& Yazdiamirkhiz, Y. (2011). The use of Persian in the EFL classroom-The case of English teaching and learning at pre-university level in Iran. English Language Teaching, 4(1), 135-140.

McDonald, C. (1993). Using the target language. Cheltenham, UK: Mary Glasgow.

McMillan, B., \& Rivers, D. J. (2011). The practice of policy: Teacher attitudes toward "English-only". System, 39, 251-263.

NaciKayaoglu, M. (2012). The use of mother tongue in foreign language teaching from teachers' practice and perspective. Pamukkale University Journal of Education, 1, 26-32.

Nation, I. S. P. (1978). Translation and the teaching of meaning: Some techniques. ELT Journal, 32(3), 171-175.

Nazary, M. (2008). The role of L1 in L2 acquisition: Attitudes of Iranian university students. Novitas Royal, 2, 138-153.

Rezvani, H., \& EslamiRasekh, A. (2011). Code-switching in Iranian elementary EFL classrooms: An exploratory investigation. English Language Teaching, 4(1), 18-25.

Schweers, C. W. (1999). Using L1 in the L2 classroom. English Teaching Forum, 37(2), 6-13.

Sharma, K. (2006). Mother tongue use in English classroom. Journal of NELTA, 11(1-2), 80-87.

Stern, H. H. (1992). Issues and options in language teaching. Oxford: Oxford University Press.

Swain, M. (1985). Communicative competence: Some roles of comprehensible input and comprehensible output in its development. In S. Gass and C. Madden (Eds.), Input in second language acquisition (pp. 235-253). Rowley, MA: Newbury House.

Turnbull, M. (2001). There is a role for the L1 in second and foreign language teaching, but... Canadian Modern Language Review, 57(4), 150-163.

Yaqubi, B., \& Pouromid, S. (2013). First language use in English language institutes: Are teachers free to alternate between L1 and L2 as means of instruction? The Journal of Teaching Language Skills (JTLS), 4(4), 127-152. 